\title{
Factors Affecting Quality of Communication Life in Older Adults: Focused on the Relationship with Quality of Life, Cognition, and Psychoemotional Aspects
}

\author{
Mi Sook Lee \\ Department of Audiology and Speech-Language Pathology, Hallym University of Graduate Studies, Seoul, Korea \\ HUGS Center for Hearing and Speech Research, Seoul, Korea
}

\begin{abstract}
노인의 의사소통 관련 삶의 질에 대한 영향 요인: 삶의 질, 인지, 심리 · 정서적 요인과의 상관성을 중심으로
이 미 숙
\end{abstract}

한림국제대학원대학교 청각언어치료학과, 한림청각언어연구소

\begin{abstract}
Purpose: The purpose of this study was to investigate the quality of communication life (QCL) in older adults as an overall context including psychological well-being, social support, communication skill, and accessibility to the communicative setting. Methods: This study was implemented on 22 normal older adults aged 65 and over. We examined the relation among QCL and other variables. These variables include quality of life, general/higher order cognition (organization/reasoning/problem solving/executive function), and psychoemotional aspects (self-efficacy/depression), which are based on factors associated with quality of life for older adults and have a direct influence on communication. The present study also explored predictors associated with QCL. Results: Quality of life, general/ higher order cognition, and self-efficacy had a significant positive correlation with QCL. A significant negative correlation between QCL and depression was observed. Education, general cognition, organization, self-efficacy, and depression were powerful predictors of QCL. Conclusion: These findings illustrate a variety of factors influencing $\mathrm{QCL}$, and contribute to drawing up measures to improve it. The result creates a momentum for a better understanding of age-related cognitive-linguistic change throughout the life span.
\end{abstract}

Key Words: Quality of communication life, Older adults, Predictors, Cognitive-linguistic change.

Received: March 7, 2019 / Accepted: May 26, 2019

Correspondence: Mi Sook Lee, Department of Audiology and Speech-Language Pathology, Hallym University of Graduate Studies, 427 Yeoksam-ro, Gangnam-gu, Seoul 06197, Korea

Tel: +82-70-8680-6961 / Fax: +82-2-3453-6618 / E-mail: mslee2018@hallym.ac.kr

\section{INTRODUCTION}

국내의 65세 이상 노인 인구는 2017년 현재 전체 인구의 $14.2 \%$ 로 '고령사회'의 기준치인 $14 \%$ 를 넘어섰다(Ministry of the Interior and Safety, 2018). 노인 인구는 2008년 이후 매년 증가세를 보여 2016년에는 65세 이상 인구(13.5\%)가 0 14세 인구(13.4\%)를 초과하기 시작했다. 이 같은 추세로 미루어 볼

(cc) This is an Open Access article distributed under the terms of the Creative Commons Attribution Non-Commercial License (https://creativecommons.org/licenses/by-nc/4.0) which permits unrestricted non-commercial use, distribution, and reproduction in any medium, provided the original work is properly cited.
때 2026년경이면 우리나라도 ‘초고령사회’가 될 것으로 예측되 고 있다(Statistics Korea, 2017). 인구의 20\% 이상이 노인으로 구성되는 초고령사회는 여러 가지 측면에서 구성원들의 삶을 변화시킬 것이다. 특히, 노년의 시기를 적극적이고 풍요롭게 보 내고자 하는 개인적·사회적 욕구가 보다 강력해질 것으로 보인 다. 이에 따라 노인의 삶의 질 문제는 전 사회적인 화두로 급부 상하고 있다.

일반적으로 '의사소통 관련 삶의 질(quality of communication life, QCL)'은 다양한 의사소통장애로 인해 손상된 의사소 통 능력이 의사소통 파트너와의 상호작용, 일상 또는 사회 생활 
에의 참여 등 개인의 삶에 미치는 영향을 의미한다(Paul et al., 2004). 이는 실어증, 마비말장애, 인지-의사소통장애 등 성인의 후천성 의사소통장애뿐 아니라 노화로 인한 인지-언어적 변화, 특정 질환으로 인한 아동 및 청소년기의 발달적 언어장애 등이 삶의 질적 측면에 미치는 개인적·심리사회적 영향을 모두 포괄 한다(Paul et al., 2004).

American Speech-Language-Hearing Association (ASHA, 2016)은 언어병리학이 자연스러운 환경에서의 의사소통 능력 을 극대화함으로써 궁극적으로 개인의 삶의 질을 향상시키는 데 기여하는 학문이라 명시하였다. 이는 의사소통 관련 삶의 질 이 학문적-임상적 차원에서 매우 핵심적인 요소임을 강조한다. 그럼에도 불구하고 삶의 질을 의사소통장애의 맥락과 어떻게 연 계시킬지에 대한 구체적인 논의는 매우 미흡한 실정이다(Cruice, 2008). 특히 노화에 따른 인지-언어적 변화로 인한 의사소통의 문제는 주관적인 인식에 근거하는 경우가 많아 삶의 질적인 차 원에서 적극적으로 논의되기가 쉽지 않다.

노인의 의사소통 관련 삶의 질은 심리적 안녕(well-being)과 사회적 건강 등 개인적 삶의 경험이라는 총체적인 맥락 속에서 고려되어야 한다(Cruice, 2008). 즉, 정신 건강, 신체적 기능, 연 령, 성별, 대처 기술과 같은 개인적 요인, 그리고 가족 및 지인의 지원과 의사소통 능력, 사회적 지지, 지역사회 내 의사소통의 접근 등 환경적 요인을 다각적으로 살펴볼 필요가 있다. 이를 통해 노화로 인한 의사소통 문제에 적극적으로 대처할 뿐 아니 라, 노년기의 전반적인 삶의 질을 향상시키는 데 기여할 수 있 다. 실제로 노인의 의사소통 능력은 일상생활의 전반적인 기능 에 관여하기 때문에, 삶의 질을 좌우하는 주요한 영향 요인에 해당한다(Forte et al., 2015). 예컨대 노인의 화용언어 능력은 신체적 건강, 사회적 관계 및 환경과 관련된 삶의 질에 크게 기 여한다(Lee, 2016).

노년기의 만족도는 주로 의사소통의 양상에 따라 달라지는 데, 이로 인해 의사소통 능력이 노인의 삶의 질을 좌우하는 경 우가 많다(Fowler et al., 2015). 실제로 50세 이상 성인들은 의 사소통 문제가 클수록 삶의 질이 저하된다는 보고가 있다(Kerr et al., 2003). 80세 이상 초고령층을 대상으로 의사소통 기술을 분석한 결과, 나이가 들수록 다양화된 의사소통 양식을 제대 로 활용하지 못하나 의사소통의 목적은 보다 뚜렷해지는 경향 을 보였다(Sims et al., 2017). 즉, 노인들은 의사소통을 통해 심 리적 안녕을 추구하고자 하는 사회적 동기(social motivation), 그리고 신체적 안녕을 위한 정보적 동기(informational motivation)가 더 확고해지는 경향이 있다.

삶의 질은 다소 모호한 개념이기 때문에 다양한 방식으로 규 정되거나 평가될 수 있다(Logsdon et al., 2002). 개인의 구체적 인 행동과 객관적인 환경, 심리적 안녕과 삶의 질에 대한 인식
자체는 상호 연계되는데, 특히 인지 문제를 갖는 노인의 경우 상관성이 더 높다고 알려져 있다(Logsdon et al., 2002). 노인의 삶의 질에 영향을 미치는 변인들로는 교육 수준, 경제력, 가족관 계, 사회활동, 인지 능력 등이 있으며, 이 중 일상생활의 광범위 한 기능을 발휘하는 데 기여하는 전반적 인지 능력은 노인의 의 사소통 관련 삶의 질의 주요 영향 요인이다(Forte et al., 2015). 즉, 노화로 인해 나타나는 인지 능력의 저하는 역동적이면서도 점진적인 양상을 띠기 때문에 노년기의 삶을 전반적으로 좌우 한다(Arrieta et al., 2018).

고차원적 인지 능력(higher order cognition)은 다차원적이고 복합적인 인지 영역으로, 추론력, 문제 해결력, 논리력, 창의력, 집행기능을 포괄한다(Lee, 2017). 다시 말해 모니터링과 통제의 역할을 하는 메타 인지적(meta-cognitive) 정보 처리 과정을 의 미한다. 노화는 이 같은 고차원적 인지 처리의 효율을 저하시킨 다(Forte et al., 2015). 65 75세의 노인을 대상으로 집행기능과 삶의 질 간의 상관성을 살펴본 결과, 억제 효율성(inhibitory efficiency), 인지 유동성(cognitive flexibility) 등 집행기능 관련 수행력이 노인의 삶의 질을 예측하는 주요 요인이었다(Forte et al., 2015). 노인의 삶의 질과 상관성이 높은 인지-언어 능력을 분석한 연구에서는 문제 해결력, 집행기능과 같은 고차원적 인 지와 화용언어 능력이 사회적 관계와 환경 관련 삶의 질에 영향 을 미쳤다(Lee, 2016). 이는 사회적 참여 정도를 강조하는 사회 적 접근으로서의 삶의 질을 중시하는 추세를 감안할 때 매우 주목할 만한 결과이다. 즉, 사회적 접근으로서의 삶의 질을 높 이기 위해서는 고차원적 인지 능력에 근간한 의사소통 기능이 필수적이다.

자기효능감(self-efficacy)이란 특정한 결과를 성취하는 데 요구되는 행동을 성공적으로 조직하고 실행할 수 있는 개인의 능력에 대한 신념이다(Bandura, 2010). 자기효능감은 개인의 정 신 건강에 큰 영향을 미치는데, 이는 보편적이거나 추상적인 지 시가 아니라 특정한 문제를 스스로 극복한 경험을 통해 강화된 다(Blazer, 2002). 노인의 자기효능감은 노화의 한계를 수용함 과 동시에 또 다른 잠재력을 인식하도록 자극함으로써 한계를 보상하는 기능을 한다(Bandura, 2010; Blazer, 2002). 반면에 노화에 대한 불안감이 의사소통과 자기효능감에 부정적인 영 향을 미칠 수도 있다(Fowler et al., 2015). 노년기에 자기효능감 을 긍정적으로 발현하기 위해서는 인지-언어 능력, 사회적 능 력 및 생산성, 정신 건강 등에 기반한 통합적 능력과 효율적인 의사소통 기술이 요구된다. 노인의 의사소통 능력과 자기효능 감, 삶의 질이 상호 연계된다는 점을 고려할 때, 이들의 기능을 증진시키는 것은 성공적인 노년의 주요 전제가 될 수 있다.

고령화 시대가 되면서 우울(depression)은 개인적 차원을 넘 어 점차 사회 인지적(social cognitive) 접근을 통해 논의되는 
추세이다. 배우자를 포함한 의미 있는 타자의 사망과 은퇴 등 으로 사회적 지지가 약화되면서 노인의 상실과 고독은 피할 수 없는 현실이 된다. 여기에 신체적인 건강의 위협까지 더해져 노 년기의 정신 건강은 여러 모로 취약해진다. 이때 의사소통은 노 화로 인한 감정적·신체적 상태를 파악하는 데 매우 중요하다. 예 를 들어 의사소통이 원활하지 않은 노인의 경우 다양한 감정적. 신체적 변화에 대해 과소평가될 우려가 있다(Chan et al., 2015). 우울과 인지-언어 능력, 의사소통 관련 삶의 질 간의 상관성은 주로 인지 문제를 갖는 노인을 대상으로 논의되거나(Arrieta et al., 2018), 청력 저하와 우울, 의사소통 관련 삶의 질 간의 관계 에 국한된 연구들이 많다(Scarinci et al., 2008). 최근에는 노인 의 우울을 극복하는 요인으로 긍정적인 의지, 적극적이고 적응 적인 자기효능감, 높은 삶의 질 등을 꼽기도 한다(Blazer, 2002).

노인의 의사소통 관련 삶의 질에 대한 접근 양상을 살펴보면 다음과 같다. 첫째, 노년기 삶의 질이라는 광범위한 맥락 내에 서 전반적 인지 능력과 고차원적 인지 능력(집행기능 등), 신체 적 건강(청력, 근육 등), 의사소통 능력, 자기효능감 등을 영향 요인으로서 분석한 연구들이다(Forte et al., 2015; Logsdon et al., 2002). 둘째, 노인의 건강 관련 삶의 질(health related quality of life)에 중점을 두고 연령, 교육 수준, 인지 및 언어 능력, 만족감, 우울 및 스트레스 등과의 상관성을 살펴보는 연구들도 있다(Ronzi et al., 2018). 셋째, 노인의 의사소통 능력과 삶의 만족도 간의 상관성에 주목한 연구들이다(Fowler et al., 2015). 즉, 노인의 의사소통 관련 삶의 질에 대한 기존의 접근들은 지 나치게 광범위한 경우가 많고, 의사소통에 초점을 둔 삶의 질 과 이에 대한 영향 요인들 간의 관계를 체계적으로 규명한 연 구들이 거의 전무하다. 따라서 노년기 삶의 질적 양상에 기여 하는 변인들에 근거하되, 의사소통에 대한 직접적인 영향 요인 을 고려하여 전반적 삶의 질, 인지 요인, 심리·정서적 요인을 본 연구의 분석 대상으로 포함시키고자 한다.

요약하면 노인의 의사소통 관련 삶의 질은 노화로 인한 삶의 질적 변화를 진단하는 데 매우 유용하다. 그럼에도 불구하고 노인의 의사소통 관련 삶의 질에 대한 영향 요인이나 예측 변 인, 주요 양상 등에 관한 국내외 연구는 매우 드문 실정이다. 이 에 본 연구에서는 신경학적 질환이 없는 정상 노인을 대상으로 의사소통 관련 삶의 질을 알아보고, 이에 영향을 주는 변인들 의 특성을 살펴볼 것이다. 또한 이들이 의사소통 관련 삶의 질 과 어떠한 상관성을 갖는지 분석하고, 노인의 의사소통 관련 삶의 질에 대한 유용한 예측 변인이 무엇인지 분석하고자 한다. 구체적인 연구 문제는 다음과 같다.

첫째, 노인의 의사소통 관련 삶의 질, 전반적 삶의 질, 전반적 및 고차원적 인지 능력, 심리·정서 영역의 특징적 양상을 알아 본다.
둘째, 노인의 의사소통 관련 삶의 질과 다른 변인들 간의 상 관성을 살펴본다.

셋째, 본 연구에서 분석 대상으로 삼은 변인들 중 노인의 의 사소통 관련 삶의 질을 가장 잘 예측하는 변인이 무엇인지 알 아본다.

\section{MATERIALS AND METHODS}

\section{연구 대상}

본 연구는 2018년 7월부터 2018년 9월까지 서울 지역에 거주 하는 65 세 이상의 노인 총 22 명을 대상으로 하였다. 이들은 서 울시 소재 노인 복지관 1 곳과 노인정 2곳, 기타 자원자들로부터 표집되었다. 연령의 분류 기준은 매우 다양하나, 본 연구에서는 65 세 이상을 노인이라 규정한 노인복지법에 근거하였다.

노인 집단의 선정 기준에는 1) 만 65세 이상의 노인, 2) $\mathrm{Ko}^{-}$ rean Mini-Mental State Examination (K-MMSE)의 정상군 규준(Kang, 2006)에 의거해 정상 범주에 속하는 노인, 3) 신경 학적 질환의 병력이 없는 노인, 4) 최소 6년 이상의 교육을 받은 노인이 포함되었다.

연령, 교육 연수, $\mathrm{K}-\mathrm{MMSE}$ 의 평균 및 표준편차, 성별 등 대 상군의 인구통계학적 특성은 Table 1에 제시하였다.

\section{연구 도구}

\section{의사소통 관련 삶의 질 평가}

노인의 의사소통 관련 삶의 질을 평가하기 위해 American Speech-Language-Hearing Association (ASHA)의 의사소통 관련 삶의 질 측정도구(ASHA QCL) (Paul et al., 2004)를 활 용하였다. QCL은 전 세계적으로 광범위하게 활용되는 의사소 통 관련 삶의 질 평가 척도로, 국내의 문화적 특성을 감안한 번 안본(Choi et al., 2011)을 참고하여 적용하였다. QCL에는 전반 적인 삶의 질에 관련된 1 개 문항, 구체적인 행동이나 기술에 관 한 17 개 문항을 합쳐 총 18 개 문항이 포함되어 있다(Table 2). 각 문항에 대해 '전혀 그렇지 않다(1점)에서 '매우 그렇다(5점)' 까지 5점의 리커트 척도(Likert scale)로 평정하며, 18개 문항에 대해 평정한 평균치를 최종적인 점수로 제시한다. 점수가 높을

Table 1. Demographic characteristics of participants

\begin{tabular}{lc}
\hline \multicolumn{1}{c}{ Characteristic } & Analytic sample $(\mathrm{n}=22)$ \\
\hline Age $(\mathrm{yr})$ & $75.55( \pm 5.33)$ \\
Gender $(\mathrm{m}: \mathrm{f})$ & $10: 12$ \\
Education level $(\mathrm{yr})$ & $9.95( \pm 3.11)$ \\
K-MMSE & $24.32( \pm 2.28)$ \\
\hline
\end{tabular}

K-MMSE: Korean Mini-Mental State Examination 
Table 2. Assessment tools

\begin{tabular}{|c|c|c|c|}
\hline Domain & Tools & Number of items & Total score \\
\hline QCL & QCL & 18 & $1-5$ \\
\hline Quality of life & WHOQOL-BREF & 26 & 100 \\
\hline \multicolumn{4}{|l|}{ Cognition } \\
\hline General cognition & K-MMSE & 30 & 30 \\
\hline Higher order cognition & CAPTBI (organization/reasoning/problem solving/executive function) & 22 & 44 \\
\hline \multicolumn{4}{|l|}{ Psycho-emotional } \\
\hline Self-efficacy & SGSES & 17 & $17-85$ \\
\hline Depression & GDS-15 & 15 & $0-15$ \\
\hline
\end{tabular}

QCL: quality of communication life, WHOQOL-BREF: World Health Organization Quality of Life-BREF, K-MMSE: Korean Mini-Mental State Examination, CAPTBI: Cognitive-pragmatic language ability Assessment Protocol for Traumatic Brain Injury, SGSES: Sherer et al. General Self-Efficacy Scale, GDS-15: 15-item Geriatric Depression Scale

수록 의사소통 관련 삶의 질이 높음을 의미한다.

\section{전반적 삶의 질 평가}

전반적인 삶의 질은 한국판 세계보건기구 삶의 질 척도 단축 형(World Health Organization Quality of Life-BREF, WHOQOL-BREF) (Min et al., 2002)을 통해 평가하였다. WHO$\mathrm{QOL}-\mathrm{BREF}$ 는 전반적 삶의 질, 신체적 건강, 심리, 사회적 관 계, 환경 등 5 개 영역에서 총 26 개 항목을 평가하는 삶의 질 관 련 척도이다(Table 2). 각 문항에 대해 5점 척도로 평정하며, 영 역별 점수 범위는 4 20점이다. 5개 영역 점수를 합산한 총점이 높을수록 삶의 질이 높음을 시사한다.

\section{전반적 및 고차원적 인지 능력 평가}

노인의 의사소통 관련 삶의 질에 미치는 인지적 영향 요인을 살펴보기 위해 전반적 인지 능력과 고차원적 인지 능력을 평가 하였다. 전반적 인지 능력은 K-MMSE를 통해 평가하였는데, 여 기에는 지남력, 기억력, 주의력 및 계산, 언어 능력(이름대기/따 라말하기/명령시행/읽기/쓰기), 시공간 능력이 포함된다(Table 2). K-MMSE는 총 30 문항으로, 각 문항당 1점씩 점수를 배당 하는 선별검사이다.

고차원적 인지 능력을 평가하기 위해 Cognitive-pragmatic language ability Assessment Protocol for Traumatic Brain Injury (CAPTBI) (Lee, 2013)를 적용하였다. CAPTBI는 정상 노인 및 신경학적 뇌 손상 환자의 인지-언어 능력을 평가하는 도구로, 9 개 영역에 대해 총 57 개 문항으로 구성되어 있다. 본 연구에서는 고차원적 인지 능력인 조직화 능력, 문제해결력, 추 론력, 집행기능에 해당하는 22 개 문항의 총점을 산정하였다 (Table 2). 문항당 2점씩 점수를 부여하며, 점수가 높을수록 고 차원적 인지 능력이 높다는 것을 의미한다.
심리·정서 영역 평가

노년층의 심리·정서적(psychoemotional) 측면에 대한 평가 는 자기효능감 및 우울의 정도를 통해 알아보았다. 자기효능감 은 Sherer et al.(1982)이 개발한 Sherer et al. General SelfEfficacy Scale (SGSES)을 사용하였다. 자기효능감의 평가를 위해 국내외적으로 빈번히 활용되는 척도로는 Sherer et al. (1982)의 자기효능감척도, Smith \& Betz(2000)의 사회적 자기효 능감척도 등이 있다. 사회적 자기효능감척도는 특정한 사회적 상황들을 포함하고 있어 노인의 전반적인 자기효능감을 평가하 고자 하는 본 연구의 취지와 일치하지 않는다. 따라서 국내 노 인 관련 선행 연구에서 가장 보편적으로 활용되어 이미 신뢰도 가 검증된 바 있는 SGSES를 본 연구에 적용하였다. SGSES는 일반적 자기효능감을 평가하는 척도로, 총 17 개 문항으로 구성 되어 있다(Table 2). 각 문항은 '전혀 그렇지 않다(1점)'에서 '매 우 그렇다(5점)'까지 리커트 5점 척도로 측정하며, 전체 문항에 대한 합산 점수가 높을수록 자기효능감이 높음을 의미한다.

우울의 정도를 평가하기 위해 단축형 노인우울척도인 15-item Geriatric Depression Scale (GDS-15) (Yesavage et al., 1982) 을 적용하였다. 이는 노인의 우울 관련 척도 중 가장 보편적으 로 활용될 뿐 아니라, 국내에서도 이미 우울증 선별검사로서의 신뢰도와 타당도가 검증된 바 있다(Park et al., 2006). 15개 문 항으로 구성된 GDS-15는 총점 15점으로 구성되어 있으며 '예/ 아니오'의 반응에 대해 문항별로 점수가 부여된다(Table 2). 높 은 점수일수록 우울의 정도가 심하다는 의미이다.

\section{연구 절차}

22 명의 노인을 대상으로 의사소통 관련 삶의 질, 전반적 삶 의 질, 전반적 및 고차원적 인지 능력, 심리·정서 영역에 대한 평 가를 각각 시행하였다. 모든 검사는 조용한 방에서 일대일로 진 행하였으며, 사전 면담을 통해 인구통계학적 정보 및 ‘읽기’ 수행 력을 확인하였다. 정상군 선별을 위해 K-MMSE를 가장 먼저 
실시한 후, QCL, SGSES, GDS-15를 각각 자가 진단하도록 하 였다. QCL과 SGSES는 각 문항별로 5점의 리커트 척도가 함께 제시되었다. CAPTBI는 검사자가 지시문 및 자극을 시·청각적 으로 제시한 후 피검자의 반응을 기록하였다. 3점 척도 $(0,1,2)$ 를 적용하여 채점하되, 문항에 따라 정반응 개수, 정·오반응 여 부, 명시화된 기준 등에 근거하여 점수를 산정하였다.

\section{통계 분석}

본 연구를 위한 통계 분석은 Statistical Product and Service Solution 25.0 (SPSS 25.0 version; IBM Corp., Armonk, NY, USA)을 활용하였다. 기술통계 결과를 통해 각 영역에 대한 수 행력을 살펴보았다. 노인의 의사소통 관련 삶의 질과 각 영향 요 인들 간의 상관성은 피어슨 상관계수(Pearson correlation $\mathrm{co}^{-}$ efficient) 분석을 활용해 알아보았다. 또한 단계적 다중선형 회 귀분석(stepwise multiple linear regression analysis)을 통해 노인의 의사소통 관련 삶의 질을 예측하는 요인이 무엇인지 분 석하였다.

\section{RESULTS}

\section{영역별 수행력}

노인을 대상으로 의사소통 관련 삶의 질, 전반적 삶의 질, 전 반적 및 고차원적 인지 능력, 심리·정서 영역에 대한 평가를 실 시한 결과는 Table 3에 제시하였다.

QCL을 통해 살펴본 의사소통 관련 삶의 질은 평균 4.13 ( \pm 0.41)으로 나타났다. QCL에 대해 국내의 표준화된 규준 점 수가 없어 선행 연구(Choi et al., 2011)에 근거하여 수행력을 비

Table 3. Outcome measures

\begin{tabular}{lrr}
\hline \multicolumn{1}{c}{ Measures } & Mean & SD \\
\hline QCL & 4.13 & 0.41 \\
WHOQOL-BREF & 71.41 & 11.62 \\
K-MMSE & 24.32 & 2.28 \\
CAPTBI & & \\
$\quad$ Organization & 8.41 & 1.14 \\
$\quad$ Reasoning & 11.82 & 2.75 \\
$\quad$ Problem solving & 10.73 & 0.98 \\
$\quad$ Executive function & 2.91 & 1.02 \\
$\quad$ Total & 33.86 & 3.52 \\
SGSES & 58.23 & 7.29 \\
GDS-15 (GDS-15 < 6) & $6.64(\mathrm{n}=8)$ & 2.15 \\
\hline
\end{tabular}

SD: standard deviation, QCL: quality of communication life, WHOQOL-BREF: World Health Organization Quality of Life-BREF, KMMSE: Korean Mini-Mental State Examination, CAPTBI: Cognitive-pragmatic language ability Assessment Protocol for Traumatic Brain Injury, SGSES: Sherer et al. General Self-Efficacy Scale, GDS15: 15-item Geriatric Depression Scale
교하였다. 본 연구 결과는 128 명의 노인을 대상으로 실시한 연 구의 평균 점수(3.63) 및 90명의 청각장애 청소년의 평균 점수 (3.62)보다 높고, 180 명의 정상 청소년의 평균 점수(4.28)보다 낮 은 것으로 분석되었다.

WHOQOL-BREF의 평가 결과 노인의 전반적 삶의 질은 평 균 71.41( \pm 11.62 )이었다. 한국판 WHOQOL-BREF (Min et al., 2002)의 표준화된 규준 점수가 '전반적 삶의 질'을 제외한 4 개 영역에만 국한된 점을 감안하여, 본 연구 결과 중 4 개 영역의 합산 점수와 비교하였다. 그 결과 본 연구에 참여한 노인의 전 반적 삶의 질에 대한 평균 점수(53.56)가 규준 점수의 평균치 (50.97)보다 다소 높게 나타났다.

$\mathrm{K}-\mathrm{MMSE}$ 를 통해 평가된 전반적 인지 능력은 평균 24.32( \pm 2.28)로 연령 및 교육 연수를 고려한 국내 규준 점수(Kang, 2006) 와 비교할 때 다소 낮은 수행력을 보였다. 또한 CAPTBI의 조직 화 능력, 문제해결력, 추론력, 집행기능에 대한 수행력을 합산한 고차원적 인지 능력의 평균은 $33.86( \pm 3.52)$ 으로 분석되었다. 이는 55 64세의 정상군을 대상으로 한 선행 연구(Lee, 2013)의 평균 점수(35.99)와 비교할 때 다소 낮은 수치에 해당하였다.

노인의 심리·정서 영역에서 자기효능감을 살펴본 결과 SGSES 의 평균은 58.23( \pm 7.29$)$ 이었다. 이는 $\operatorname{Imam(2007)ㅇㅣ~ㅈㅔㅅㅣㅎㅏㄴ~ㄱㅠ~}$ 준 점수(59.28)보다 다소 낮은 수치에 해당하였다. 또한 GDS-15 를 통해 평가한 우울의 정도는 6.64( \pm 2.15)로, 55세 이상의 노인 을 대상으로 한 국내 선행 연구(Cho et al., 1999)의 평균 점수 (8.22)보다 낮았다. 그러나 임상에서 보편적으로 활용되는 절단 점(cut-off score)인 6점(Yesavage et al., 1982)보다는 높게 나 타났다.

\section{의사소통 관련 삶의 질과 다른 변인들 간 상관성}

노인의 의사소통 관련 삶의 질과 다른 변인들 간의 상관성을 살펴본 결과 전반적 삶의 질, 전반적 인지 능력, 고차원적 인지 능력, 자기효능감과 모두 정적 상관을 보였다 $(p<0.01)$. 이들 4 개 변인의 상관계수 범위는 0.806에서 0.962로 의사소통 관련 삶의 질과 '매우 높은 정도의 정적 상관성이 있었다. 우울의 정 도에 대한 상관계수는 -0.948 로 의사소통 관련 삶의 질과 '매

Table 4. Correlations between $\mathrm{QCL}$ and other variable

\begin{tabular}{lc}
\hline \multirow{2}{*}{ Variables } & QCL \\
\cline { 2 - 2 } & Pearson correlation coefficient ${ }^{\dagger}$ \\
\hline Quality of life & $0.806^{*}$ \\
General cognition & $0.948^{*}$ \\
Higher order cognition & $0.841^{*}$ \\
Self-efficacy & $0.962^{*}$ \\
Depression & $-0.948^{*}$ \\
\hline
\end{tabular}

${ }^{*} p<0.01,{ }^{\dagger} 95 \%$ confidence intervals. QCL: quality of communication life 
Table 5. Predictors of quality of communication life

\begin{tabular}{|c|c|c|}
\hline Predictors & $\begin{array}{l}\text { Standardized } \\
\beta \text { coefficient }^{*}\end{array}$ & $\begin{array}{c}\text { Adjusted } \\
\mathrm{R}^{2}\end{array}$ \\
\hline \multicolumn{3}{|l|}{ Demographic factor } \\
\hline Education & $0.954^{*}$ & 0.906 \\
\hline \multicolumn{3}{|l|}{ Cognitive factor } \\
\hline General cognition & $0.816^{*}$ & 0.910 \\
\hline Organization (higher order cognition) & $0.194^{\dagger}$ & 0.910 \\
\hline \multicolumn{3}{|l|}{ Other factor } \\
\hline Self-efficacy & $0.584^{*}$ & 0.949 \\
\hline Depression & $-0.414^{*}$ & 0.949 \\
\hline
\end{tabular}

${ }^{*} p<0.01,{ }^{\dagger} p<0.05,{ }^{*} 95 \%$ confidence intervals

우 높은 부적 상관성을 나타내었다 $(p<0.01)$. 즉, 우울의 정도 가 심할수록 의사소통 관련 삶의 질이 낮은 것으로 분석되었다.

$\mathrm{QCL}$ 과 5개 변인들 간의 상관성은 Table 4와 같다.

\section{의사소통 관련 삶의 질의 예측 변인}

노인의 의사소통 관련 삶의 질을 가장 잘 예측하는 변인이 무엇인지를 분석한 결과는 Table 5 에 제시하였다. 연령, 성별, 교육 연수를 포함한 인구통계학적 요인 중 교육 연수가 의사소 통 관련 삶의 질을 예측하는 주요 변인이었다 $(p<0.01)$. 또한 전반적 인지 능력 $(p<0.01)$, 그리고 고차원적 인지 능력 중 조 직화 능력 $(p<0.05)$ 이 노인의 의사소통 관련 삶의 질을 예측 하는 인지 요인으로 분석되었다. 기타 요인 중에는 자기효능감 및 우울의 정도가 노인의 의사소통 관련 삶의 질에 대한 주요 예측 변인이었다.

\section{DISCUSSIONS}

의사소통은 한 개인이 삶 전반에 걸쳐 겪는 장단기적인 어려 움과 적응의 문제를 성공적으로 다루는 데 핵심적인 기능이다 (Nussbaum, 2007). 고령화 시대에서 노년기는 더 이상 잉여적 이거나 수동적인 의미가 아니라, 의미 있는 타자와의 의사소통 을 통해 난제들을 적극적으로 해결함은 물론 공식적·비공식적 과업을 달성하는 역동적인 의미이다. 따라서 노인의 의사소통 능력은 삶의 질을 좌우하는 매우 강력한 변인에 해당한다. 즉, 노년기 삶의 질의 핵심은 지속적인 성장 과정 및 사회적 맥락에 서 이루어지는 의사소통이다(Cohen, 2001). 따라서 의사소통 관련 삶의 질이 전제되지 않고 전반적인 삶의 질을 높이는 데 필요한 요소들을 획득하거나 유지할 수 없다(Nussbaum, 2007).

노인의 의사소통 관련 삶의 질에 대한 영향 요인은 매우 다 양하다. 의사소통 관련 삶의 질은 의사소통 기능, 인지-언어적 처리, 신체적 건강, 사회적 참여 등 생리적·개인적·사회적 영역 의 경험적 소산이므로, 그 특징적 양상을 이해하기 위해서는
다차원적 변인들을 살펴보아야 한다(Baylor et al., 2005). 특히 기존의 연구들은 노년기 삶의 질이라는 광범위한 맥락 내에서 연령, 교육 등의 인구통계학적 요인, 전반적 인지 능력, 신체적 요인, 스트레스나 만족감 등을 분석한 연구들이 대부분이다 (Forte et al., 2015; Logsdon et al., 2002; Ronzi et al., 2018). 노인의 의사소통 능력을 다룬 경우에도 의사소통 관련 삶의 질 에 주목하거나 직접적인 영향 요인을 살펴보는 데 한계가 있었 다(Fowler et al., 2015). 이에 본 연구에서는 노인의 삶의 질과 직결되는 다양한 요인들을 고려하되, 의사소통 관련 삶의 질에 보다 직접적으로 연계되는 변인들로서 전반적 삶의 질, 전반적 및 고차원적 인지 능력, 심리·정서 영역을 살펴보았다.

본 연구에서 노인의 의사소통 관련 삶의 질과 전반적 삶의 질은 매우 높은 정적 상관을 보였다. 노화로 인해 의사소통에 어려움을 겪게 되면 삶의 질이 전반적으로 저하된다(Naqvi et al., 2013). 65세 이상의 정상 노인 66명을 대상으로 화용언어 능력과 삶의 질 간의 상관성을 살펴본 연구에 따르면 화용언어 가 사회적 관계 및 환경, 신체적 건강 등과 관련된 삶의 질과 큰 상관성을 보였다(Lee, 2016). 즉, 일상생활의 기능적인 의사 소통 능력을 반영하는 화용언어가 노인의 삶의 질 전반에 관여 한다. 예를 들어 노인은 문맥을 적절히 유지하는 능력이 떨어져 장황하고 반복적인 발화를 산출한다(Lee, 2017). 또한 비유언 어나 상징언어에 대한 맥락적 해석과 사회적 의사소통 등 전반 적인 화용언어 능력이 저하된다(Lee, 2017). 이러한 기능적 의 사소통 능력이 삶의 질과 직결되기 때문에, 노인을 대상으로 언 어 자극을 지속적으로 제공하는 다양한 예방적 조치들이 증가 하는 추세이다(Naqvi et al., 2013). 본 연구 결과를 토대로 노 화에 따라 의사소통 기능이 저하되거나 주관적 인지장애(subjective cognitive impairment), 인지-언어적 저하에 대한 주관 적 호소(subjective complaints) 등을 보이는 노인들을 대상으 로 임상 전(preclinical) 단계에서 삶의 질을 높일 수 있는 중재 방법을 고안할 수 있을 것이다.

노화에 따른 인지-언어적 변화와 의사소통 관련 삶의 질 간 의 상관성은 다각적인 차원에서 논의되어 왔다. 신경학적 차원 에서는 노화가 뇌의 구조적·기능적 변화를 초래한다는 데 주 목한다. 정상적인 노화 과정에서 뇌의 무게와 용적은 10 15\% 까지 감소하며, 전전두엽(prefrontal cortex) 및 전두엽, 두정엽 내 회백질(gray matter)의 용량이 줄면서 급격한 뇌 위축(brain atrophy)이 발생한다(Raz, 2005). 기능적인 측면에서 노인은 기 억력을 관장하는 뇌 영역의 편재화(lateralization)가 약화되는 경향을 보인다(Cabeza, 2002). 즉, 양 반구를 모두 활용해 노화 로 인한 신경인지적 결함을 보완하고자 한다. 또한 전전두엽과 측두엽의 기능이 두드러지게 변화하고(Cabeza, 2002), 전전두 엽과 전두엽 내 백질(white matter)의 용량 및 효율성이 달라지 
면서 복합적인 인지 변화를 초래한다. 노인들의 언어 능력이 저 하되는 것도 인지적 자원을 효율적으로 할당하는 능력이나 기 억의 용량 자체가 변화하는 데 기인한다(Braver et al., 2005).

노화로 인해 작업기억, 집행기능 등이 저하되면서 원활한 의 사소통에 어려움을 겪는다(Lee, 2017). 본 연구에서 노인의 의 사소통 관련 삶의 질은 전반적 인지 능력 및 고차원적 인지 능 력과 상관성이 매우 높았다. 특히 조직화 능력, 문제해결력, 추 론력, 집행기능과 같은 고차원적 인지 능력은 복합적인 인지언어적 처리에 광범위하게 관여한다는 점에서 본 결과가 시사 하는 바가 크다. 최근에는 노화가 작업기억과 집행기능에 미치 는 영향이 강조되면서 언어와 의사소통의 변화를 이들과의 연 계 속에서 파악하려는 시도가 많아지고 있다(McDowd et al., 2011). McDowd et al.(2011)은 젊은 층과 노년층의 다양한 구어 유창성을 처리 속도, 억제, 작업기억 용량, 구어 능력과 비교함 으로써 작업기억 용량이 낮은 노인일수록 처리의 효율성에 더 의존하게 된다고 보고했다. 즉, 젊은 층의 집행기능은 다양한 표상을 저장하는 작업기억 용량과 관련되는 반면, 노년층은 저 하된 작업기억에 정보를 추가하거나 삭제할 수 있는 효율성의 영향을 더 크게 받는다.

따라서 의사소통에 근간하는 다양한 수준의 인지-언어 능력 을 파악하는 것은 의사소통 관련 삶의 질을 높일 수 있는 가장 효율적인 방법이다. 특히 최근에는 노인의 일상생활과 직결되 는 기능적인 문제들을 의사소통과 연계시킴으로써 질적 삶을 도모하고자 하는 시도가 많아지고 있다. 원활한 신체 및 사회, 여가 활동에 요구되는 핵심적인 인지-언어 능력을 분석하거나, 노인의 주요 의사소통 파트너를 분석 대상으로 삼아 삶의 질적 요인들을 다룬 연구들이 그 예이다(Forte et al., 2015). 여기서 중요한 것은 노화에 따른 인지-언어적 변화가 역동적이고 지속 적이며 변이적인 양상을 띠므로, 이에 대처하는 삶의 기능적 양상 또한 동일한 맥락에서 논의되어야 한다는 점이다. 요컨대 의사소통 관련 삶의 질은 노년의 삶에서 초래되는 인지 및 언 어 능력의 변화를 얼마나 역동적이고 적극적으로 다루는가에 달려있다(Nussbaum, 2007).

본 연구에서는 노인의 심리·정서적 측면이 의사소통 관련 삶 의 질에 영향을 미치는지 살펴보았다. 그 결과 자기효능감은 의 사소통 관련 삶의 질과 매우 높은 정적 상관을 보였으며, 우울 은 매우 높은 부적 상관성을 나타내었다. 삶에 영향을 주는 스 스로의 능력에 대한 믿음을 의미하는 자기효능감은 노인들이 자기 스스로를 돌보는 능력과 직결된다(Bandura, 2010). 또한 자기효능감은 노년의 삶에 대한 스스로의 만족도를 높이는 데 기여한다. 노화로 인한 인지-언어적 변화를 조정하는 '중재자' 로서의 역할을 수행하는 것은 자기효능감의 순기능 중 하나이 다(Anderson et al., 2010). Scult et al.(2015)은 자기효능감과
우울, 전반적인 건강 등이 노년기 삶의 광범위한 영역을 좌우한 다고 보고한 바 있다. 자기효능감이나 우울과 같은 심리사회 적·정서적 측면을 고려하여 전반적인 건강에 기여하고자 하는 노력이 고령화 사회의 당면 과제인 이유도 바로 여기에 있다 (Scult et al., 2015). 특히 의사소통은 심리사회적 맥락 내에서 의 상호작용이므로(Cohen, 2001), 자기효능감이 높을수록 노 화에 따른 변화에 잘 대처할 뿐 아니라 다양한 유형의 기능적 저하를 완화시킬 수 있다(Scult et al., 2015). 자기효능감이 갖 는 상쇄 효과와 잠재적인 보존 능력, 회복력 등은 노년기 삶의 질을 높이는 필수 요소에 해당한다(Nussbaum, 2007).

노인의 의사소통 관련 삶의 질은 우울과 의사소통 간의 상관 성을 통해 예측할 수 있다(Chan et al., 2015). 우울의 정도가 심하면서 동시에 의사소통이 저하된 노인의 경우 정신적-신체 적 고통에 더 민감하다. Thomas et al.(2013)은 실어증 환자를 대상으로 의사소통과 우울 간의 상관성을 살펴보았는데, 우울 의 정도는 실어증의 중재 효과를 예측하는 주요 변인이었다. 이 처럼 의사소통 관련 삶의 질에 영향을 미치는 우울은 자기효능 감과도 크게 연관된다(Blazer, 2002). 일상에서의 다양한 접근 을 통해 자기효능감을 강화시킴으로써 우울과 같은 심리사회 적 요인을 다루는 것도 바로 이 때문이다. 즉, 강화된 심리사회 적 자원은 삶의 안녕을 추구하는 데 크게 기여할 수 있다. 특히 타인과의 의사소통에 어려움을 겪거나 의사소통에 대한 의지 가 없는 노인의 경우 우울을 포함한 심리·정서적 조치가 필수적 이다(Chan et al., 2015). 이는 삶에 대한 긍정적인 태도가 자기효 능감과 사회적 지지, 의사소통 상호작용을 조정함으로써 궁극적 으로 삶의 질을 높일 수 있다는 데 근거한다.

본 연구에서 노인의 의사소통 관련 삶의 질을 가장 잘 예측 하는 인구통계학적 변인은 교육 연수였고, 전반적 인지 능력과 조직화 능력이 주요한 인지적 예측 변인이었다. 교육 수준은 문 화와 함께 인지-언어적 변화에 대한 견고한 영향 요인(crystallized-influenced)에 해당하는데, 성인기 이후 노년에 이르기까 지 고르게 영향을 미친다(Anstey \& Low, 2004). 이는 나이가 들수록 생물학적 요인, 질병, 상해, 유전과 같은 유동적 영향 요 인(fluid-influenced)이 약화되는 것과 대조적이다(Anstey \& Low, 2004). 본 연구는 교육 수준과 전반적 인지 능력, 의사소 통 간의 연계성을 살펴봄으로써 교육 수준이 노화에 따른 언 어-언어적 변화에 크게 기여함을 입증하였다. 고차원적 인지 능 력 중에는 조직화 능력이 의사소통 관련 삶의 질을 가장 잘 예 측하는 변인이었다. 과제의 범주화나 단계별 순서화를 포함하는 조직화 능력은 하나의 체계라기보다 '처리 능력'에 해당하는데, 노화는 이 같은 처리의 효율성에 부정적으로 작용한다(Lee, 2017). 예컨대 구어 및 문어의 처리에 있어 노인이 어려움을 겪 는 것은 인지-언어적 처리 속도가 느리고 효율성이 떨어지기 
때문이다(Cabeza, 2002). 이는 의사소통의 기능을 질적으로 저 하시키고 궁극적으로 삶의 질에 부정적인 영향을 미친다.

자기효능감과 우울의 정도 역시 노인의 의사소통 관련 삶의 질을 예측하는 주요 변인이었다. 이는 노화에 대한 불확실한 감정과 두려움이 의사소통 기능과 자기효능감을 저하시킨다는 보고와 일맥상통한다(Fowler et al., 2015). Ronzi et al.(2018) 은 2만7천여 개의 문헌을 통해 다차원적인 인지-언어 활동이 노인의 삶의 질을 어떻게 증진시키는지 살펴보았다. 중재 효과 가 긍정적으로 나타난 영역으로는 우울, 심리적 안녕, 스트레스 및 정신 건강 등이었다. 즉, 전반적인 심리·정서적 요인은 인지언어 능력에 기반한 의사소통 관련 삶의 질을 크게 좌우한다. 따라서 노인의 심리·정서적 문제를 다룰 때에는 삶의 질이라는 맥락 내에서 의사소통 기능의 저하나 의사소통 환경의 문제까 지 다각적으로 고려할 필요가 있다.

요컨대 의사소통 능력은 전 생애에 걸쳐 변화의 과정을 겪는 다. 이러한 변화를 다루고 조정하는 능력이 만족스러운 삶의 질을 성취하고 유지하는 데 매우 중요하다. 따라서 노화에 따 른 의사소통 능력의 저하나 변화에 대한 단순한 예측에만 머무 르지 말고, 노인의 삶의 질을 보장하는 데 있어 의사소통 능력 을 어떻게 연계시킬 것인지 숙고할 필요가 있다.

본 연구의 임상적 함의는 다음과 같다. 첫째, 노인의 의사소 통 관련 삶의 질과 전반적 삶의 질, 전반적 및 고차원적 인지 능력, 심리·정서 영역과의 상관성을 살펴봄으로써 의사소통 관 련 삶의 질에 영향을 미치는 변인들이 무엇인지 규명하였다. 둘 째, 노인의 의사소통 관련 삶의 질을 예측할 수 있는 인구통계 학적, 인지적, 기타 변인들을 분석함으로써 의사소통 관련 삶의 질을 제고할 수 있는 방안을 구체화하는 데 기여하였다. 셋째, 고령화 시대의 화두인 노인의 삶의 질 문제를 의사소통과 연계 하여 조명함으로써 노화에 따른 인지-언어적 변화를 삶의 과 정 속에서 총체적으로 고려해야 한다는 인식을 제고하는 계기 를 마련하였다.

본 연구의 한계점은 다음과 같다. 첫째, 노인의 의사소통 관 련 삶의 질과 상관성을 갖는 변인으로서 전반적 삶의 질, 전반 적 및 고차원적 인지 능력, 심리·정서 영역을 살펴보았다. 또한 의사소통 관련 삶의 질에 대한 예측 변인으로서 연령, 성별, 교 육 연수를 포함한 인구통계학적 요인, 전반적 인지 능력, 조직 화 능력, 문제해결력, 추론력, 집행기능과 같은 고차원적 인지 능력, 전반적 삶의 질, 자기효능감, 우울을 포함한 기타 요인을 분석 대상으로 삼았다. 향후 연구에서는 노인의 의사소통 관련 삶의 질에 영향을 미치는 다양한 변인들을 포함시킬 필요가 있 다. 예컨대 어휘, 구문, 담화 등 언어의 하위 영역별 변인, 인지언어적 처리에 광범위하게 관여하는 작업기억이나 청력 관련 변인, 사회적 지지, 스트레스 등의 심리사회적 변인 등도 고려
할 수 있다(Baylor et al., 2005). 둘째, 본 연구에 참여한 노인의 평균연령은 75.55( \pm 5.33)세였으며, 연령 범주는 66 84세로 매우 광범위하였다. 노화로 인한 의사소통의 변화는 연령에 따 라 민감한 양상을 보이므로(Lee, 2017), 연령별로 세분화된 노 인 집단을 대상으로 의사소통 관련 삶의 질을 살펴보아야 할 것이다. 추후에는 65세부터 74세까지의 젊은 노인(young-old), 75세부터 84세까지의 중고령(middle-old) 노인, 85세 이상의 초고령(old-old) 노인 집단 등으로 분류하여 의사소통 관련 삶 의 질의 집단별 차이, 각 집단별 예측 변인 등을 파악할 필요가 있다. 셋째, 노화가 신경학적 변화의 과정이라는 점을 감안할 때 신경병리학적 장애군과의 비교 연구가 요구된다. 예를 들어 알츠하이머병으로 인한 인지-의사소통장애, 뇌졸중으로 인한 실어증 등 신경병리학적 원인에 의한 장애군의 의사소통 관련 삶의 질을 상호 비교할 수 있을 것이다(Thomas et al., 2013). 넷째, 본 연구는 수도권이라는 특정 지역에 국한하여 제한적인 인원의 대상자들로부터 표집된 자료에 근거하므로, 국내 노인 의 의사소통 관련 삶의 질을 논의하기에 다소 무리가 있을 수 있다. 향후에는 표집 지역 및 대상자 수의 확충을 통해 연구 결 과의 신뢰도와 타당도를 보완할 것이다.

본 연구에서는 신경학적 질환이 없는 정상 노인을 대상으로 의사소통 관련 삶의 질을 알아보고, 이에 영향을 주는 변인들 과의 상관성을 분석하였다. 또한 노인의 의사소통 관련 삶의 질 을 예측하는 유용한 변인이 무엇인지 살펴보았다. 이를 통해 의 사소통 관련 삶의 질을 제고하는 방안을 구체화하는 데 기여하 였다. 또한 노인의 삶의 질 문제를 의사소통과 연계함으로써 노 화에 따른 인지-언어적 변화를 삶의 과정 속에서 총체적으로 고려해야 한다는 인식을 증진시키는 계기를 마련할 수 있었다.

중심 단어 : 의사소통 관련 삶의 질·노인·예측 변인· 인지-언어적 변화.

\section{Ethical Statement}

We explained exactly the purpose and process of this study to all participants in advance. And they agreed to participate in it. This study was approved by the Institutional Review Board (\#HUGSAUD461850).

\section{Acknowledgments}

N/A

\section{Declaration of Conflicting Interests}

There are no conflict interests.

\section{Funding}

N/A

\section{ORCID iD}

Mi Sook Lee

https://orcid.org/0000-0001-9255-565X 


\section{REFERENCES}

American Speech-Language-Hearing Association. (2016). Scope of Practice in Speech-Language Pathology. ASHA. Retrieved from https://www.asha. org/policy/SP2016-00343/.

Anderson, E. S., Winett, R. A., Wojcik, J. R., \& Williams, D. M. (2010). Social cognitive mediators of change in a group randomized nutrition and physical activity intervention: Social support, self-efficacy, outcome expectations and self-regulation in the guide-to-health trial. Journal of Health Psychology, 15(1), 21-32.

Anstey, K. J. \& Low, L. F. (2004). Normal cognitive changes in aging. Australian Family Physician, 33(10), 783-787.

Arrieta, H., Rezola-Pardo, C., Echeverria, I., Iturburu, M., Gil, S. M., Yanguas, J. J., et al. (2018). Physical activity and fitness are associated with verbal memory, quality of life and depression among nursing home residents: Preliminary data of a randomized controlled trial. BMC Geriatrics, $18(1), 80$

Bandura, A. (2010). Self-efficacy. In Weiner, I. B. \& Craighead, W. E. (4th ed.). The Corsini Encyclopedia of Psychology. Hoboken, NJ: John Wiley \& Sons.

Baylor, C. R., Yorkston, K. M., \& Eadie, T. L. (2005). The consequences of spasmodic dysphonia on communication-related quality of life: A qualitative study of the insider's experiences. Journal of Communication Disorders, 38(5), 395-419.

Blazer, D. G. (2002). Self-efficacy and depression in late life: A primary prevention proposal. Aging and Mental Health, 6(4), 315-324.

Braver, T. S., Satpute, A. B., Rush, B. K., Racine, C. A., \& Barch, D. M. (2005). Context processing and context maintenance in healthy aging and early stage dementia of the Alzheimer's type. Psychology and Aging, 20(1), 33-46.

Cabeza, R. (2002). Hemispheric asymmetry reduction in older adults: The HAROLD model. Psychology and Aging, 17(1), 85-100.

Chan, W. C., Kwan, C. W., \& Chi, I. (2015). Moderating effect of communication difficulty on the relationship between depression and pain: A study on community-dwelling older adults in Hong Kong. Aging and Mental Health, 19(9), 829-834.

Cho, M. J., Bae, J. N., Suh, G. H., Hahm, B. J., Kim, J. K., Lee, D. W., et al. (1999). Validation of geriatric depression scale, Korean version(GDS) in the assessment of DSM-III-R major depression. Journal of Korean Neuropsychiatric Association, 38(1), 48-63.

Choi, H. Y., Kim Y. W., Rha, D. W., \& Kim, H. H. (2011). The quality of communication life scale-Korean version. Communication Sciences and Disorders, 16(3), 388-396.

Cohen, G. D. (2001). The Creative Age : Awakening Human Potential in the Second Half of Life. Indianapolis, IN: Quill.

Cruice, M. (2008). The contribution and impact of the International Classification of Functioning, Disability and Health on quality of life in communication disorders. International Journal of Speech-Language Pathology, 10(1-2), 38-49.

Forte, R., Boreham, C. A., De Vito, G., \& Pesce, C. (2015). Health and quality of life perception in older adults: The joint role of cognitive efficiency and functional mobility. International Journal of Environmental Research and Public Health, 12(9), 11328-11344.

Fowler, C., Gasiorek, J., \& Giles, H. (2015). The role of communication in aging well: Introducing the communicative ecology model of successful aging. Communication Monographs, 82(4), 431-457.

Imam, S. S. (2007). Proceedings of the Redesigning Pedagogy-Culture, Knowledge and Understanding Conference: Sherer et. al. General SelfEfficacy Scale: Dimensionality, Internal Consistency, and Temporal Stability. Singapore.

Kang, Y. W. (2006). A normative study of the Korean-Mini Mental State Examination (K-MMSE) in the elderly. Korean Journal of Psychology: General, 25(2), 1-12.

Kerr, J., Engel, J., Schlesinger-Raab, A., Sauer, H., \& Hölzel, D. (2003). Communication, quality of life and age: Results of a 5-year prospective study in breast cancer patients. Annals of Oncology, 14(3), 421-427.

Lee, M. S. (2013). Development and application of Cognitive-pragmatic language ability Assessment Protocol for Traumatic Brain Injury (CAPTBI) (Unpublished doctoral dissertation). Yonsei University, Seoul.

Lee, M. S. (2016). The relationship between cognitive-linguistic ability and quality of life in older adults. Journal of Special Education and Rehabilitation Science, 55(4), 143-161.

Lee, M. S. (2017). Linguistic predictors of cognition in aging. Journal of Special Education and Rehabilitation Science, 56(2), 237-262.

Logsdon, R. G., Gibbons, L. E., McCurry, S. M., \& Teri, L. (2002). Assessing quality of life in older adults with cognitive impairment. Psychosomatic Medicine, 64(3), 510-519.

McDowd, J., Hoffman, L., Rozek, E., Lyons, K. E., Pahwa, R., Burns, J., et al. (2011). Understanding verbal fluency in healthy aging, Alzheimer's disease, and Parkinson's disease. Neuropsychology, 25(2), 210-225.

Min, S. K., Kim, K. I., \& Park, I. H. (2002). Korean Version of WHOQOL. Seoul: Hana mpc.

Ministry of the Interior and Safety. (2018). Resident registration demographics. Seoul: Ministry of the Interior and Safety.

Naqvi, R., Liberman, D., Rosenberg, J., Alston, J., \& Straus, S. (2013). Preventing cognitive decline in healthy older adults. Canadian Medical Association Journal, 185(10), 881-885.

Nussbaum, J. F. (2007). Life span communication and quality of life. Journal of Communication, 57(1), 1-7.

Park, H. S., Deung Jung, Y. J., Lee, C. I., Oh, J. E., Hong, S. H., \& Cho, C. Y. (2006). Comparing various short-form geriatric depression scales in elderly patients. Korean Journal of Family Medicine, 27(5), 364-369.

Paul, D. R., Frattali, C. M., Holland, A. L., Thompson, C. K., Caperton, C. J., \& Slater, S. C. (2004). Quality of Communication Life Scale. Rockville, MD: ASHA.

Raz, N. (2005). The aging brain observed in vivo: Differential changes and their modifiers. In Cabeza, R., Nyberg, L., \& Park, D. Cognitive Neuroscience of Aging: Linking Cognitive and Cerebral Aging (pp. 19-57). New York, NY: Oxford University Press.

Ronzi, S., Orton, L., Pope, D., Valtorta, N. K., \& Bruce, N. G. (2018). What is the impact on health and wellbeing of interventions that foster respect and social inclusion in community-residing older adults? A systematic review of quantitative and qualitative studies. Systematic Reviews, 7(1), 26.

Scarinci, N., Worrall, L., \& Hickson, L. (2008). The effect of hearing impairment in older people on the spouse. International Journal of Audiology, 47(3), 141-151.

Scult, M., Haime, V., Jacquart, J., Takahashi, J., Moscowitz, B., Webster, A., et al. (2015). A healthy aging program for older adults: Effects on selfefficacy and morale. Advances in Mind-Body Medicine, 29(1), 26-33.

Sherer, M., Maddux, J. E., Mercandante, B., Prentice-dunn, S., Jacobs, B., \& Rogers, R. W. (1982). The Self-efficacy Scale: Construction and validation. Psychological Reports, 51(2), 663-671.

Sims, T., Reed, A. E., \& Carr, D. C. (2017). Information and communication technology use is related to higher well-being among the oldestold. The Journals of Gerontology, Series B: Psychological Sciences and Social Sciences, 72(5), 761-770.

Smith, H. M. \& Betz, N. E. (2000). Development and validation of a scale of perceived social self-efficacy. Journal of Career Assessment, 8(3), 283301.

Statistics Korea. (2017). Future Demographic Estimates. Daejeon: Statistics Korea.

Thomas, S. A., Walker, M. F., Macniven, J. A., Haworth, H., \& Lincoln, N. B. (2013). Communication and Low Mood (CALM): A randomized controlled trial of behavioural therapy for stroke patients with aphasia. Clinical Rehabilitation, 27(5), 398-408.

Yesavage, J. A., Brink, T. L., Rose, T. L., Lum, O., Huang, V., Adey, M., et al. (1982). Development and validation of a geriatric depression screening scale: A preliminary report. Journal of Psychiatric Research, 17(1), 37-49. 